\title{
MRNA Expression
}

National Cancer Institute

\section{Source}

National Cancer Institute. mRNA Expression. NCI Thesaurus. Code C18888.

The synthesis or transcription of messenger RNA. 